\title{
Dill Weed Oil
}

National Cancer Institute

\section{Source}

National Cancer Institute. Dill Weed Oil. NCI Thesaurus. Code C107303.

The essential oil of Anethum graveolens. Dill weed oil is used as treatment for digestive complaints. 